\title{
Slow-flow phenomena following lower limb paclitaxel- and sirolimus-coated balloon angioplasty in the setting of chronic limb threatening ischaemia - a case series
}

\author{
Tjun Y. Tang ${ }^{1,2} \wedge$, Muhammad S. B. Sulaiman ${ }^{3}$, Shereen X. Y. Soon ${ }^{1} \wedge$, Charyl J. Q. Yap ${ }^{1 \wedge}$, Ankur Patel ${ }^{4}$, \\ Tze T. Chong ${ }^{1 \wedge}$ \\ ${ }^{1}$ Department of Vascular Surgery, Singapore General Hospital, Singapore, Singapore; ${ }^{2}$ Duke-NUS Graduate Medical School, Singapore, Singapore; \\ ${ }^{3}$ Department of Radiography, Singapore General Hospital, Singapore, Singapore; ${ }^{4}$ Department of Vascular Interventional Radiology, Singapore \\ General Hospital, Singapore, Singapore
}

Correspondence to: Tjun Y. Tang, MD, FRCS (Gen), FAMS. Senior Consultant - Vascular \& Endovascular Surgeon, Associate Professor - Duke-NUS Medical School, Department of Vascular Surgery, Singapore General Hospital, Level 5, Academia 20 College Road, Singapore 169856, Singapore. Email: tang.tjun.yip@singhealth.com.sg.

\begin{abstract}
The Achilles heel of plain old balloon angioplasty (POBA) is neointimal hyperplasia (NIH) and restenosis, caused from the barotrauma of ballooning. Drug-coated balloons using a paclitaxel-based platform (PCB) have been shown to retard the restenotic process, using the anti-proliferative effects of paclitaxel, and give longer vessel patency. This is important in the setting of chronic limb threatening ischemia (CLTI) and for the protracted wound healing process in these frail patients. However, during PCB application, more than $50 \%$ of the drug is lost downstream, a phenomenon termed particulate embolization. This is thought to account for the slow- or no-flow phenomenon encountered after PCB use. Recent data suggest that slow-flow phenomenon was associated with a lower target lesion revascularisation rate and worse amputation free survival (AFS). The use of sirolimus coated balloons (SCB) to impede the NIH cascade has been less well studied but recent data suggested excellent short-term efficacy and found no slow flow phenomenon with their use in the tibial arteries in CLTI patients. Aim of this case series is to highlight the difference in flow phenomena using PCB and SCB elution in the setting of CLTI. We evaluated the use of parametric colour coding and time attenuation curves (TAC) as a quantitative measure of blood flow. SCB may have an advantage over PCB use in the peripheral vasculature because of a reduced incidence of slow flow phenomenon following drug elution.
\end{abstract}

Keywords: Drug coated balloon (DCB); lower limb angioplasty; chronic limb threatening ischaemia; flow phenomenon; case report

Submitted Jun 15, 2021. Accepted for publication Nov 04, 2021.

doi: 10.21037/qims-21-633

View this article at: https://dx.doi.org/10.21037/qims-21-633

\section{Introduction}

Chronic limb threatening ischemia (CLTI) is the most advanced stage of the peripheral arterial disease (PAD) mosaic, defined by the presence of PAD in combination with rest pain, gangrene, or lower limb ulceration of more than 2 weeks duration and patients have high risk of major lower limb amputation and mortality (1). Despite no proven superiority over open surgical bypass in terms of

^ ORCID: Tjun Y Tang, 0000-0002-8524-7912; Shereen X. Y. Soon, 0000-0003-3057-5983; Charyl J. Q. Yap, 0000-0002-8606-0842; Tze

T. Chong, 0000-0001-5927-4303. 
amputation free survival (AFS) and overall mortality (2), an endovascular angioplasty-first revascularization strategy is recommended for lower limb short arterial occlusions or stenotic lesions for CLTI (3) because of its minimal footprint and repeatability, in what is a challenging cohort of patients with multiple co-morbidities.

Shear stress created during balloon angioplasty triggers vessel wall inflammation, initiating hypertrophic neointimal hyperplasia (NIH) and restenosis (4). Drug coated balloons (DCBs) have gained popularity over the past five years because of the "leave nothing behind" concept. They have been shown to reduce late lumen loss, binary restenosis, and target lesion revascularization (TLR) in the treatment of femoropopliteal disease, compared to conventional angioplasty (5). Majority of DCBs use a paclitaxel-based platform (PCB) and paclitaxel reduces late restenosis by exerting antiproliferative effects to inhibit NIH (6). However, during DCB application, more than $50 \%$ of the drug is lost downstream, a phenomenon termed particulate embolization (7). This is thought to account for the slowor no-flow phenomenon encountered after DCB use with paclitaxel. Recent data suggest the incidence rate of the slow-flow phenomenon was approximately $8.0 \%$ after DCB use with PCB in the peripheral vasculature and was associated with complete total occlusion lesions, poor tibial vessel runoff, longer total DCB length used and in the setting of CLTI (8). Furthermore, those patients who experienced the slow-flow phenomenon had worse short term clinical outcomes such as freedom from TLR, AFS and overall survival. Recent data has pointed to a possible risk of a higher mortality signal (9) and lower AFS (10) in patients receiving paclitaxel-coated devices for PAD, although no subsequent meta-analysis using patient-level data has corroborated this finding.

Sirolimus is another potent antiproliferative agent that prevents activation of smooth muscle cells after vascular injury. Its anti-restenotic effects have been well-studied in sirolimus eluting stent devices in the coronary circulation, where it been shown to be safe and more effective than paclitaxel devices (11), with a wider therapeutic window and a higher safety margin (12). Data for application of sirolimus in the peripheral circulation using sirolimus coated balloons (SCB) is less well studied, although the PRESTIGE study recently reported first in the world experience using the Selution Sustained Limus Release (SLR) ${ }^{\mathrm{TM}}$ (M. A. MedAlliance SA, Nyon, Switzerland) sirolimus-eluting balloon, for treating complex below the knee atherosclerotic stenotic lesions in CLTI patients from Singapore (13).
The aim of this case series is to highlight the difference in flow phenomena using PCB and SCB elution in the setting of CLTI, after appropriate lesion preparation using conventional plain old balloon angioplasty (POBA). We evaluated the use of parametric colour coding and analysis of time attenuation curves (TAC) as a real time quantitative measure of flow after plain angioplasty and drug elution.

We present the following article in accordance with the AME Case Series checklist (available at https://dx.doi. org/10.21037/qims-21-633).

\section{Methods}

This is a single-centre retrospective case series. The following cases were performed in Singapore General Hospital, a tertiary vascular centre. All procedures performed in studies involving human participants were in accordance with the ethical standards of the institutional and/or national research committee(s) and with the Helsinki Declaration (as revised in 2013). Written informed consent was obtained from the patients for publication of this case series and accompanying images. A copy of the written consent is available for review by the editorial office of this journal.

\section{Digital subtraction angiography (DSA)}

DSAs were performed using a robotic flat panel, multi-axis, interventional angiographic system (Artis Zeego, Siemens Healthcare, Forchheim, Germany) in a hybrid operating theatre by the senior author (TYT). A $2 \mathrm{~mL} / \mathrm{s}$ bolus of $50 \%$ diluted iohexol contrast agent (Visipaque, GE Healthcare, Amersham, UK) was administered using an injection system (MEDRAD Mark 7 Arterion $^{\circledR}$, Bayer Radiology, USA), via a downhill common femoral artery $10 \mathrm{~cm} 5 \mathrm{Fr}$ sheath for the digitally subtracted arterial sequences. Arterial access was gained using ultrasound guidance through the mid common femoral artery. No boluses of heparinised saline were allowed during the DSA run at each stage. Before and after POBA and post DCB (PCB/SCB) intervention DSA images at the exact location (whether femoro-popliteal or tibial) were acquired using a variable frame rate (1-4 frames per s), until all foot arteries were fully visualised and subsequently allowed to wash out, to permit meaningful comparison.

Pre-dilatation with a conventional non-DCB catheter for at least 2 minutes was mandatory for all target lesions (diameter 1:1 sizing to the reference vessel) once crossed with a wire. DCB was only implanted if there was less than 

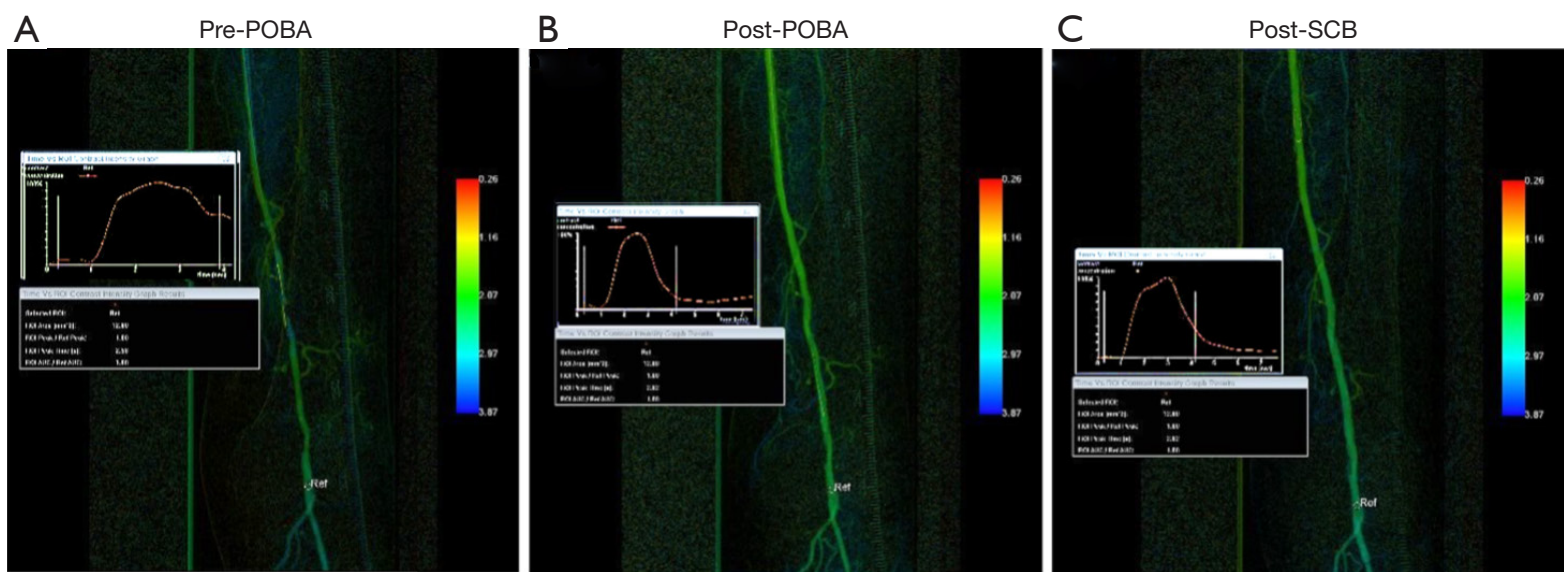

Figure 1 Case 1 using sirolimus coated balloon (SCB) drug elution post-plain old balloon angioplasty (POBA) in the superficial femoral artery (SFA). (A) Pre-intervention run showing multi focal stenoses along the proximal- and mid-SFA, showing slow washout on the parametric colour coding and time attenuation curve (TAC). (B) Post-POBA angiography run showing faster washout of contrast. (C) PostSCB angiography run showing no slow flow phenomenon with similar TAC.

$30 \%$ recoil. For DCB sizing, the nominal balloon diameter had to match the reference vessel diameter distal to the target lesion. To secure full lesion coverage, DCB length was required to be $>1 \mathrm{~cm}$ longer at each end than the predilatation balloon to avoid geographical miss, with a DCB inflation time $>90 \mathrm{~s}$ for the first dilatation. Balloons that were greater than $150 \mathrm{~mm}$ in length, a 3-min inflation was employed to maximise drug transfer to the arterial wall. In cases when two or more DCBs were required, overlapping of DCBs by at least $1 \mathrm{~cm}$ was accomplished.

\section{Parametric colour coding and TAC analysis}

Parametric colour coding of pre- and post-plain balloon angioplasty and post DCB elution DSA acquisitions were analysed using readily available post-processing software (Syngo iFlow, Siemens Healthcare, Germany). Parametric colour coding assigns a particular colour to each pixel within the two-dimensional DSA image, from red (fast flow) to blue (slow flow) based on the time delay between contrast injection and maximum vessel opacification, showing the contrast flow over time. The post-processing software can also generate a TAC for a specific region of interest (ROI) distal to the lesion treated or on the main run off blood vessel into the foot. This is a graph that compares contrast intensification against time. The ROI is the washout of contrast through the vessel (downslope) and the slope steepness represents the washout velocity (steeper the slope the faster the washout).

\section{Case presentations}

Case 1

A 76-year-old community ambulant Chinese male with type II DM and end stage renal failure (ESRF) on haemodialysis. Previous history of ischaemic heart disease (IHD) with a recent ejection fraction of $55 \%$ on echocardiography. He was admitted with a 3 -week history of a non-healing calf wound. The pre-operative Duplex ultrasound found multi focal stenoses $(>75 \%)$ along the proximal- and midsuperficial femoral artery (SFA) with 2 vessel run-off via the peroneal and posterior tibial artery. This was confirmed on the pre-intervention run (Figure 1A). Once the SFA stenoses were traversed with a wire, the lesion was predilated with a $5 \mathrm{~mm} \times 180 \mathrm{~mm}$ high pressure non-compliant balloon (Jade ${ }^{\mathrm{TM}}$, OrbusNeich, Hong Kong, China) for 3 minutes. Selution SLR ${ }^{\mathrm{TM}} \mathrm{SCB}(5 \mathrm{~mm} \times 150 \mathrm{~mm} \times 2)$ was then applied to cover the whole lesion length. Each balloon was inflated for 2 minutes to optimise maximal sirolimus transfer to the arterial wall. Similar to the post POBA DSA run (Figure 1B), there was no slow flow phenomenon noticed on the angiogram run after DEB elution (Figure 1C). The washout curve did not change from post POBA to post SCB.

\section{Case 2}

A 64-year-old female with a 5-day history of big toe gangrene. Past medical history included type II DM and ESRF (on haemodialysis). The diseased proximal anterior 

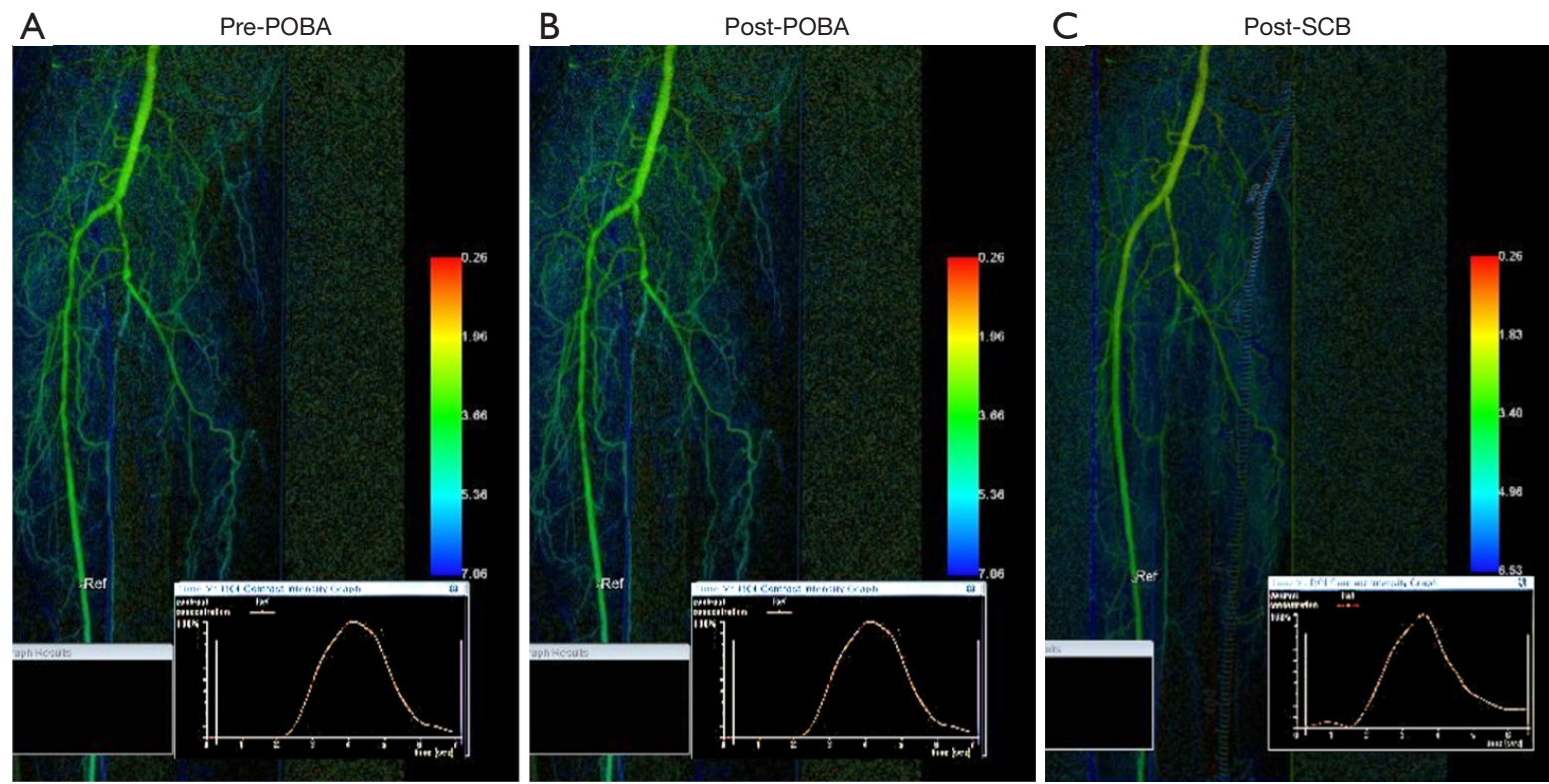

Figure 2 Case 2 using sirolimus coated balloon (SCB) drug elution in the anterior tibial artery. (A) Pre-intervention (post-plain balloon angioplasty, POBA) angiography run showing diseased proximal anterior tibial artery. (B) Post-POBA angiography run showing faster washout of contrast. (C) Post-SCB run showing no slow flow phenomenon with similar colour intensity on parametric colour coding.

tibial artery (ATA) was the angiosome of interest (Figure 2A). The ATA lesion was prepared with $3 \mathrm{~mm} \times 120 \mathrm{~mm}$ (proximally) high pressure non-compliant balloon (Jade ${ }^{\mathrm{TM}}$, OrbusNeich) for 3 minutes (Figure $2 B$ ). Selution SLR ${ }^{\mathrm{TM}}$ SCB $(3 \mathrm{~mm} \times 150 \mathrm{~mm})$ was subsequently used to balloon the entire lesion length from origin to mid ATA. There was no evidence of slow phenomenon on the angiogram run after SCB elution (Figure 2C) and the flow was similar to the post POBA DSA run (Figure 2B). The washout curves did not change from post POBA and post SCB.

\section{Case 3}

81-year-old female with 1 week history of right sided rest pain. Co-morbidities included type II DM, ESRF (on peritoneal dialysis) and IHD (EF $=45 \%$ one year ago). Preoperative Duplex ultrasound found multi-focal tight SFA disease from origin to proximal popliteal artery (Figure $3 A$ ). Two-vessel run off via a patent peroneal and ATA. The SFA lesions were crossed and the lesion was predilated with a $5 \mathrm{~mm} \times 240 \mathrm{~mm}$ high pressure non- compliant plain balloons (Jade ${ }^{\mathrm{TM}}$, OrbusNeich) for 3 minutes duration (Figure 3B). A high dose PCB (Passeo-18 Lux ${ }^{\mathrm{TM}}$, Biotronik, Berlin, Germany; $3.0 \mu \mathrm{g} / \mathrm{mm}^{2}$ ) was then used to coat the lesion from SFA origin to P1 for 2 minutes to maximise drug transfer to the adventitial layer of the artery. Slow flow phenomenon was noticed on the DSA after PCB application (Figure 3C), with the washout curve demonstrating longer washout time following PCB.

\section{Case 4}

A 59-year-old female with Type II DM and ESRF (on haemodialysis). Admitted with a 9-day history of a plantar heel wound and CTO of the ATA and posterior tibial artery (PTA) on Duplex ultrasound pre-operatively. PTA had no target outflow vessel and decision was made to open the ATA, which was approached from an ipsilateral antegrade position with a wire and the entire stenosis was predilated with $3 \mathrm{~mm} \times 240 \mathrm{~mm}$ (proximally) and $2.5 \mathrm{~mm} \times 80 \mathrm{~mm}$ (distally) high pressure non-compliant plain balloons (Jade ${ }^{\mathrm{TM}}$, OrbusNeich) each for 3 minutes (Figure 4A). Low dose PCBs (Lutonix ${ }^{\mathrm{TM}}$, Bard BD. Minnesota, US; $\left.2 \mu \mathrm{g} / \mathrm{mm}^{2}\right)(3 \mathrm{~mm} \times 120 \mathrm{~mm} \times 2$ and $2.5 \mathrm{~mm} \times 120 \mathrm{~mm})$ were then used to treat the whole target lesion from ATA origin to DPA. Each balloon was gain inflated for 2 minutes duration. Blood flow was much faster after POBA (Figure $4 B$ ) but the flow was noticed to be slightly slower after PCB use (Figure 4C), with the washout curve being slightly slower than after POBA DSA run. 


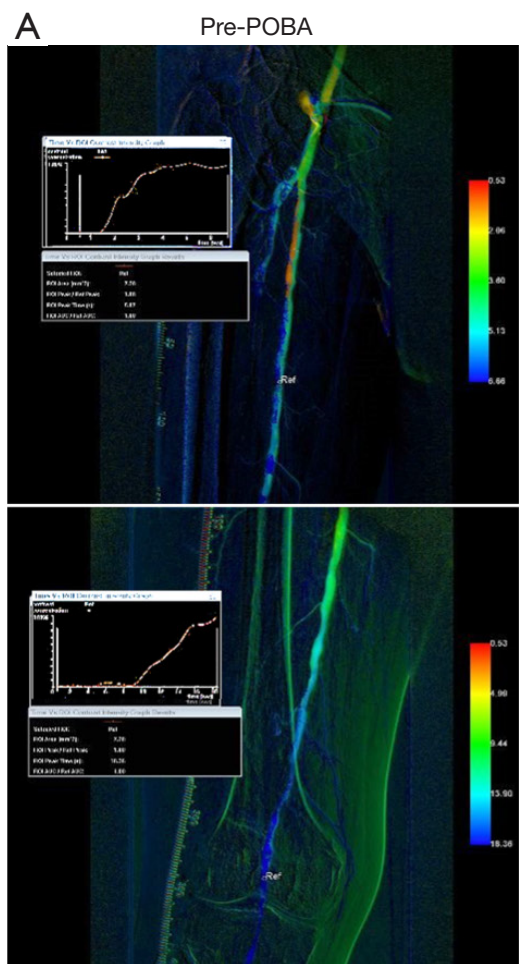

B

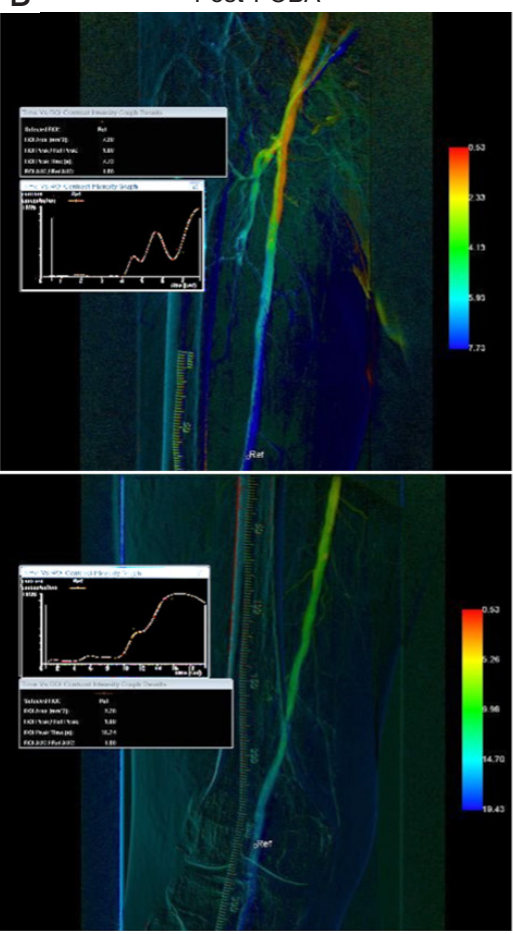

C

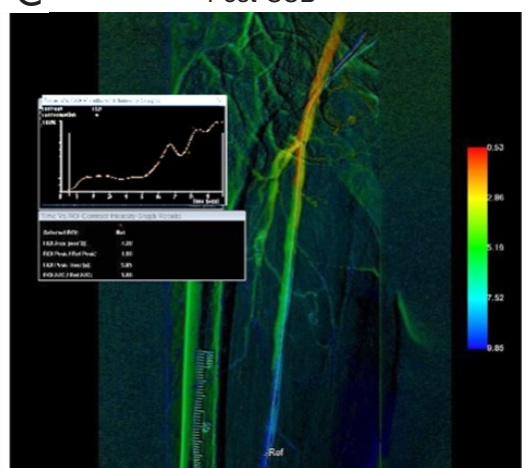

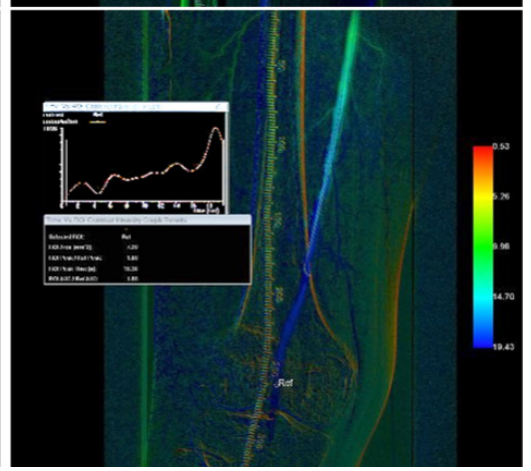

Figure 3 Case 3 using a high dose paclitaxel coated balloon (PCB) in the superficial femoral artery (SFA). (A) Pre-intervention angiography run showing multi-focal tight SFA disease from origin to proximal popliteal artery. (B) Post-plain balloon angioplasty (POBA) angiography run showing faster blood flow. (C) Post high dose PCB run demonstrating reduced flow and washout.

\section{Discussion}

We have highlighted 4 CLTI cases showing the differential effect of using SCB and PCB in the peripheral vasculature in both the SFA and tibial vessels. Flow data showed slower flow after PCB use, especially using a high dose $\mathrm{PCB}$, compared to POBA whereas the flow was unaffected after SCB application. Non-target paclitaxel embolism in distal arteries can lead to arterial occlusion, non-healing wounds and acute hypersensitivity reactions (14), more so in CLTI patients due to limited blood flow reserve and poor outflow vessels (15). A meta-analysis comparing PCBs with POBA RCTs for infra-popliteal disease in the CLTI setting reported significantly worse AFS in the DCB arm, more evident in high-dose $\left(3.0-3.5 \mu \mathrm{g} / \mathrm{mm}^{2}\right)$ than low-dose $\left(2.0 \mu \mathrm{g} / \mathrm{mm}^{2}\right)$ devices, as seen in our cases (10). Paclitaxel embolism was postulated to be the underlying mechanism for worse AFS. Particulate formation after PCB use may be different depending on the type of PCB used and the excipient and coating technology of the drug on the balloon platform. A preclinical study evaluating the downstream effect in healthy swine reported a significantly higher number of vascular changes downstream from arteries treated with the IN.PACT Admiral DCB (Medtronic, Dublin, Ireland) compared with the Lutonix DCB (Bard BD. Minnesota, USA) (16). IN.PACT Admiral DCB uses a higher paclitaxel dose than Lutonix DCB, and coating and excipient technology is different. Likewise, in a rabbit model, the Ranger ${ }^{\mathrm{TM}}$ (Boston Scientific, Marlborough, USA) - a low dose DCB, was associated with significantly lower non-target paclitaxel embolization rates compared to four other DCBs (17).

The SELUTION SL TM SCB gained Conformite Europeene (CE) Mark in February 2020 and is embedded with sirolimus, at a dose density of $1 \mu \mathrm{g} / \mathrm{mm}^{2}$. There is no drug coating excipient but micro-reservoirs made of a biodegradable phospholipid polymer complex are used and are attached with a proprietary Cell Adherent Technology amphipathic transfer membrane to the balloon surface. This serves the function of protecting the sirolimus filled micro-reservoirs during balloon insertion, placement across the lesion and balloon inflation. During balloon inflation, the transfer membrane containing the micro-reservoirs releases from the balloon surface and adheres to the vessel 



Figure 4 Case 4 using a low dose paclitaxel coated balloon (PCB) in the anterior tibial artery. (A) Pre-intervention angio run showing complete total occlusion of the anterior tibial artery. (B) Post-plain balloon angioplasty (POBA) angiography run showing faster blood flow to foot. (C) Post low dose PCB run demonstrating similar parametric colour coding but with slightly reduced washout speed on the time attenuation curve (TAC).

lumen. PRESTIGE using this novel SCB demonstrated an admirable 6 -month $81.5 \%$ primary tibial patency and freedom from clinically driven TLR of $83.3 \%$ (13). AFS was high $(84 \%)$ and complete wound healing was achieved in $81 \%$, which is comparable, if not superior compared not only with an open surgical bypass strategy for limb salvage (18) but also previously published data using PCB in lower limb endovascular revascularization for tissue loss (19). This may be related to their finding of no incidence of slow flow phenomenon, after Selution SLR ${ }^{\mathrm{TM}}$ use, even during the situation of SCB inflation in the below ankle territory ( $40 \%$ cases), where the blood vessels are much smaller and would be less tolerant to distal embolization and occlusion. The authors suggested that an advantage of this balloon had been the noticeable absence of significant flaking of the sirolimus drug or carrier from the balloon after inflation, based on the flow on the angiographic runs after drug elution.

\section{Conclusions}

Slow flow phenomenon has been associated with a worse clinical outcome if encountered during DCB angioplasty and the pathophysiology is thought to be related to particulate embolization into the microvasculature of the foot causing vasospasm or blockage. This may be critical in the CLTI setting, where there may be concomitant microvascular disease in the foot and outflow reserve already limited. SCB may have an advantage over PCB use in the peripheral vasculature because of a reduced incidence of slow flow phenomenon following drug elution. A larger study comparing SCB and PCB (high and low dose) is now required using quantitative flow imaging to confirm this 
finding and to see if this affects long term AFS.

\section{Acknowledgments}

Funding: None.

\section{Footnote}

Reporting Checklist: The authors have completed the AME Case Series checklist. Available at https://dx.doi. org/10.21037/qims-21-633

Conflicts of Interest: All authors have completed the ICMJE uniform disclosure form (available at https://dx.doi. org/10.21037/qims-21-633). TYT and TTC report that the Manufacturer (M.A. MedAlliance SA) has provided physician- initiated research grants to Singapore General Hospital and honoraria to them for speaking engagements. The other authors have no conflicts of interest to declare.

Ethical Statement: The authors are accountable for all aspects of the work in ensuring that questions related to the accuracy or integrity of any part of the work are appropriately investigated and resolved. All procedures performed in studies involving human participants were in accordance with the ethical standards of the institutional and/or national research committee(s) and with the Helsinki Declaration (as revised in 2013). Written informed consent was obtained from the patients for publication of this case series and accompanying images. A copy of the written consent is available for review by the editorial office of this journal. Where illustrations include recognizable individuals, living or deceased, great care was taken to ensure that consent for publication has been given. Patient anonymity was preserved.

Open Access Statement: This is an Open Access article distributed in accordance with the Creative Commons Attribution-NonCommercial-NoDerivs 4.0 International License (CC BY-NC-ND 4.0), which permits the noncommercial replication and distribution of the article with the strict proviso that no changes or edits are made and the original work is properly cited (including links to both the formal publication through the relevant DOI and the license). See: https://creativecommons.org/licenses/by-nc-nd/4.0/.

\section{References}

1. Conte MS, Bradbury AW, Kolh P, White JV, Dick F,
Fitridge R, Mills JL, Ricco JB, Suresh KR, Murad MH; GVG Writing Group. Global vascular guidelines on the management of chronic limb-threatening ischemia. J Vasc Surg 2019;69:3S-125S.e40.

2. Popplewell MA, Davies HOB, Narayanswami J, Renton M, Sharp A, Bate G, Patel S, Deeks J, Bradbury AW. A Comparison of Outcomes in Patients with Infrapopliteal Disease Randomised to Vein Bypass or Plain Balloon Angioplasty in the Bypass vs. Angioplasty in Severe Ischaemia of the Leg (BASIL) Trial. Eur J Vasc Endovasc Surg 2017;54:195-201.

3. Aboyans V, Ricco JB, Bartelink MEL, Björck M, Brodmann M, Cohnert T,, et al. 2017 ESC Guidelines on the Diagnosis and Treatment of Peripheral Arterial Diseases, in collaboration with the European Society for Vascular Surgery (ESVS): Document covering atherosclerotic disease of extracranial carotid and vertebral, mesenteric, renal, upper and lower extremity arteriesEndorsed by: the European Stroke Organization (ESO)The Task Force for the Diagnosis and Treatment of Peripheral Arterial Diseases of the European Society of Cardiology (ESC) and of the European Society for Vascular Surgery (ESVS). Eur Heart J 2018;39:763-816.

4. Schillinger M, Minar E. Restenosis after percutaneous angioplasty: the role of vascular inflammation. Vasc Health Risk Manag 2005;1:73-8.

5. Caradu C, Lakhlifi E, Colacchio EC, Midy D, Bérard X, Poirier M, Ducasse E. Systematic review and updated meta-analysis of the use of drug-coated balloon angioplasty versus plain old balloon angioplasty for femoropopliteal arterial disease. J Vasc Surg 2019;70:981-995.e10.

6. Lindquist J, Schramm K. Drug-Eluting Balloons and Drug-Eluting Stents in the Treatment of Peripheral Vascular Disease. Semin Intervent Radiol 2018;35:443-52.

7. Torii S, Yahagi K, Mori H, Harari E, Romero ME, Kolodgie FD, Young B, Ragheb A, Virmani R, Finn AV. Biologic Drug Effect and Particulate Embolization of Drug-Eluting Stents versus Drug-Coated Balloons in Healthy Swine Femoropopliteal Arteries. J Vasc Interv Radiol 2018;29:1041-1049.e3.

8. Shirai S, Hirano K, Mori S, Makino K, Honda Y, Tsutsumi M, Sakamoto Y, Kobayashi N, Araki M, Yamawaki M, Ito Y. Frequency, predictors, and effect of the slow-flow phenomenon after drug-coated balloon angioplasty for femoropopliteal lesions. Heart Vessels 2021;36:1818-24.

9. Katsanos K, Spiliopoulos S, Kitrou P, Krokidis M, Karnabatidis D. Risk of Death Following Application of Paclitaxel-Coated Balloons and Stents in the 
Femoropopliteal Artery of the Leg: A Systematic Review and Meta-Analysis of Randomized Controlled Trials. J Am Heart Assoc 2018;7:e011245.

10. Katsanos K, Spiliopoulos S, Kitrou P, Krokidis M, Paraskevopoulos I, Karnabatidis D. Risk of death and amputation with use of paclitaxel-coated balloons in the infrapopliteal arteries for treatment of critical limb ischemia: a systematic review and meta-analysis of randomized controlled trials. J Vasc Interv Radiol 2020;31:202-12.

11. Navarese EP, Tandjung K, Claessen B, Andreotti F, Kowalewski M, Kandzari DE, Kereiakes DJ, Waksman R, Mauri L, Meredith IT, Finn AV, Kim HS, Kubica J, Suryapranata H, Aprami TM, Di Pasquale G, von Birgelen C, Kedhi E. Safety and efficacy outcomes of first and second generation durable polymer drug eluting stents and biodegradable polymer biolimus eluting stents in clinical practice: comprehensive network meta-analysis. BMJ 2013;347:66530.

12. Wessely R, Schömig A, Kastrati A. Sirolimus and Paclitaxel on polymer-based drug-eluting stents: similar but different. J Am Coll Cardiol 2006;47:708-14.

13. Tang TY, Yap C, Soon SXY, Chan SL, Lee QS, Yap HY, Tay HTL, Chong TT. World's First Experience Treating TASC II C and D Tibial Occlusive Disease Using the Selution SLR Sirolimus-Eluting Balloon: Six-Month Results From the PRESTIGE Study. J Endovasc Ther 2021;28:555-66.

Cite this article as: Tang TY, Sulaiman MSB, Soon SXY, Yap CJQ, Patel A, Chong TT. Slow-flow phenomena following lower limb paclitaxel- and sirolimus-coated balloon angioplasty in the setting of chronic limb threatening ischaemia-a case series. Quant Imaging Med Surg 2022;12(3):2058-2065. doi: 10.21037/qims-21-633
14. Lake E, Twigg M, Farquharson F. Acute hypersensitivity reaction to femoral drug-coated balloons. Vasa 2017;46:223-5.

15. Torii S, Jinnouchi H, Sakamoto A, Romero ME, Kolodgie FD, Virmani R, Finn AV. Comparison of Biologic Effect and Particulate Embolization after Femoral Artery Treatment with Three Drug-Coated Balloons in Healthy Swine Model. J Vasc Interv Radiol 2019;30:103-9.

16. Kolodgie FD, Pacheco E, Yahagi K, Mori H, Ladich E, Virmani R. Comparison of Particulate Embolization after Femoral Artery Treatment with IN.PACT Admiral versus Lutonix 035 Paclitaxel-Coated Balloons in Healthy Swine. J Vasc Interv Radiol 2016;27:1676-1685.e2.

17. Boitet A, Grassin-Delyle S, Louedec L, Dupont S, Lamy E, Coggia M, Michel JB, Coscas R. An Experimental Study of Paclitaxel Embolisation During Drug Coated Balloon Angioplasty. Eur J Vasc Endovasc Surg 2019;57:578-86.

18. Schanzer A, Hevelone N, Owens CD, Belkin M, Bandyk DF, Clowes AW, Moneta GL, Conte MS. Technical factors affecting autogenous vein graft failure: observations from a large multicenter trial. J Vasc Surg 2007;46:1180-90; discussion 1190.

19. Liistro F, Porto I, Angioli P, Grotti S, Ricci L, Ducci K, Falsini G, Ventoruzzo G, Turini F, Bellandi G, Bolognese L. Drug-eluting balloon in peripheral intervention for below the knee angioplasty evaluation (DEBATE-BTK): a randomized trial in diabetic patients with critical limb ischemia. Circulation 2013;128:615-21. 